\title{
Evaluation of the SBA-15 materials ability to accumulation of 4-chlorophenol on carbon paste electrode
}

\author{
Anna Deryło-Marczewska ${ }^{1}$ (1) Małgorzata Zienkiewicz-Strzałka ${ }^{1}$ • \\ Katarzyna Skrzypczyńska ${ }^{2}$ Andrzej Świątkowski ${ }^{2}$ Krzysztof Kuśmierek ${ }^{2}$
}

Received: 8 November 2015/Revised: 3 February 2016/Accepted: 5 February 2016/Published online: 12 February 2016

(C) The Author(s) 2016. This article is published with open access at Springerlink.com

\begin{abstract}
The adsorption of 4-chlorophenol (4-CP) from an aqueous solution on three ordered mesoporous silica materials (commercial unmodified SBA-15-Sigma, synthesized unmodified SBA-15 and amino-functionalized SBA-15- $\mathrm{NH}_{2}$ ) was studied. The adsorption isotherms were analyzed using the Generalized Langmuir equation taking into account the energetic heterogeneity. The adsorption capacities of the mesoporous silicas increased in order: SBA-15 < SBA-15-Sigma $<$ SBA-15- $\mathrm{NH}_{2}$. The materials were used for the modification of the carbon paste electrodes (CPEs) for detection of 4-CP based on differential pulse voltammetry. Different parameters that affects the DPV signal such as scan rate, accumulation time and paste composition were investigated. Compared with the bare (graphite) CPE, the SBA-15 modified electrodes greatly increased the oxidation peak current of 4-CP, showing strong signal enhancement effects. The SBA-15- $\mathrm{NH}_{2}$ modified CPE showed a larger peak current and higher sensitivity for the 4-CP in comparison with the SBA-15 and SBA-15-Sigma modified carbon paste electrodes. The results showed high usefulness of the ordered mesoporous silica materials as an electrode modifiers in the electroanalytical techniques.
\end{abstract}

Keywords Mesoporous silica - 4-Chlorophenol · Adsorption · Carbon paste electrode

Anna Deryło-Marczewska annad@hektor.umcs.lublin.pl

1 Faculty of Chemistry, M. Curie-Skłodowska University, 20-031 Lublin, Poland

2 Institute of Chemistry, Military University of Technology, 00-908 Warsaw, Poland

\section{Introduction}

Mesoporous silica materials are characterized by high values of specific surface area, large pore volume and their pore structure consists of uniform canals formed in regular space networks. In this group of materials the SBA-15 silicas with hexagonal symmetry having wider mesopores receive much attention because of the possibility of application in the processes which are controlled by diffusion in pore system of a solid (Zhao et al. 1998). The SBA-15 materials with well organized structure are very useful as adsorbents (Gibson 2014a, b), catalyst supports (Huirache-Acuña et al. 2013), supports of active substances (Vallet-Regi et al. 2007; Wang 2009) or sensors (Melde et al. 2008). Moreover, the surface properties of these types of materials can be easily modified, e.g. by functionalization with various groups (Chong and Zhao 2003) in order to attain the highest effectiveness in a given application. Recently, mesoporous materials (unmodified as well as functionalized) have been used as carbon paste electrode (CPE) modifiers. The advantages of CPEs, are as follows: low cost, low residual current, speed of getting a new reproducible surface and possibilities of miniaturization. CPEs can be employed in connection with various electrochemical techniques such as voltammetry and its variants. The often used method is differential pulse voltammetry (DPV). DPV is extremely useful to detect trace levels of organic and inorganic analytes. In this technique, there are a series of regular voltage pulses superimposed on the potential linear sweep or stair steps. Just before each potential change and late in the pulse life, the currents are recorded. The current difference is then plotted against the applied potential. In the differential pulse voltammogram, the height of the current peak can be directly proportional to the concentration of corresponding 
analytes. The peak potential varies with different analytes, which can also be used to distinguish the detected species. DPV can help improve the sensitivity of the detection and the resolution of the voltammogram. Therefore, this technology has also been widely used for the electroanalysis.

Moreover, CPEs are easily prepared and modified by adding the modifier directly to a carbon paste during its preparation step (Švancara et al. 2009). Many applications in electrochemistry using SBA-15 as modifier have been reported. Recently, SBA-15 was used as a modifier of carbon paste electrodes (CPEs) for detection and determination of metal ions (Cesarino et al. 2007a, b; Cesarino et al. 2008; Zhang et al. 2010), cardiac troponin I (Guo et al. 2005), diethylstilbestrol (Xie et al. 2014), epinephrine (Yi et al. 2013), catechol (Dong et al. 2012), hydroquinone (Dong et al. 2012), oxalic acid (Raoof et al. 2015) as well as dihydroxybenzene (Zhang et al. 2011), aminophenol (Duan et al. 2013) and naphthol (Zheng et al. 2015) isomers. On the other hand the amino-functionalized mesoporous silicas have attracted great attention in many fields of science. Some examples include catalysis, adsorption and removal of heavy metals as well as holding of various molecules and bioactive materials (Xie et al. 2009, Zhang et al. 2007). It is known that amine groups are effective for the adsorption of organic molecules because of their possible charge association and great adsorption energy. Some examples relate to the adsorption of chlorophenols like 2-chlorophenol (2CPh) and 2,4-dichlorophenol (2,4-DCPh) on a mesoporous silica functionalized by 3-(trimethoxysilyl)propylamine and tetraethylenepentamine (Ghaffari et al. 2014). Amino modiefied SBA-15 material was used also as an effective nanosorbent for the removal of halophenols from wastewater (Anbia and Amirmahmoodi 2011).

This paper describes the application of SBA-15 mesoporous materials as the modifiers of carbon paste electrodes. In the work presented, two unmodified SBA-15 silicas and one amino-functionalized SBA-15 ordered mesoporous silicas in the preparation of CPEs were used. The best conditions for a differential pulse voltammetric (DPV) procedure were optimized and the modified CPEs were applied in the detection of 4-chlorophenol. 4-CP is known as one of the most cumbersome and harmful water pollutants which toxicity is independent of the environment and type of organism. Moreover, the products of its degradation are toxic similarly as the initial compound. The chlorinated phenol was chosen as the target contaminant because it is poisonous to aquatic life, plants and humans at low level (Igbinosa et al. 2013) and is commonly found in drinking water (Michalowicz 2005). The 4-chlorophenol is harmful by inhalation for human at a level equal to $10,000 \mathrm{mg} / \mathrm{m}^{3}$ (Gigiena i Sanitariya 1964). $\mathrm{LD}_{50}$ (Lethal Dose) test, which suggests the death of $50 \%$ (one half) of a group of test animals, for rat indicates the amount of 4-chlorofenol at a level $260 \mathrm{mg} / \mathrm{kg}$ by oral route (Clayton 1967). As an example of poisoning of aquatic species by 4-chlorophenol two types of invertebrate (pink hydra (Hydra vulgaris) and green hydra (Hydra viridissima)) were selected as a model of life organisms. LC test (Lethal Concentration) suggests sensitivity to 4-chlorophenol on a level $32 \mathrm{mg} / \mathrm{L}$ and $45 \mathrm{mg} / \mathrm{L}$ for pink and green hydra respectively (Pollino and Holdway 1999). The electrochemical determination of 4-CP at CPEs modified with montmorillonite (Yang et al. 2008), $\mathrm{TiO}_{2}$ (Wan et al. 2009) as well as carbonaceous materials including carbon black (Kusmierek et al. 2015), activated carbons (Kusmierek et al. 2015), carbon nanotubes (Lipinska et al. 2014) and reduced graphene oxide (Lipinska et al. 2014) has been described. However, the detection and determination of 4-CP using ordered mesoporous silica SBA-15 modified CPEs has not yet been reported.

\section{Experimental}

\subsection{Chemicals and instruments}

The 4-chlorophenol (2,4-D, $\geq 99 \%)$, triblock copolymer Pluronic P123 $\left(\mathrm{M}_{\mathrm{n}} \sim 5800\right)$, tetraethoxysilane (TEOS, $98 \%$ ), aminopropyltriethoxysilane (APTES, $\geq 98 \%$ ) and graphite powder were from Sigma-Aldrich (St. Louis, USA). The ethanol (96\%), hydrochloric acid (35\%), sodium sulfate $(\geq 99 \%)$, potassium hexacyanoferrate(III) and potassium nitrate were obtained from Avantor Performance Materials (Gliwice, Poland). Three mesoporous silica materials were used in this studies - commercially available mesoporous silica received from Sigma-Aldrich (SBA-15-Sigma), and the two silicas (unmodified SBA-15 and amino-functionalized SBA-15- $\mathrm{NH}_{2}$ ) synthesized according to the procedure described in Sect. 2.2. Stock standard solutions of $4-\mathrm{CP}\left(0.5 \mathrm{mmol} / \mathrm{dm}^{3}\right)$ were prepared in $0.1 \mathrm{~mol} / \mathrm{dm}^{3}$ sodium sulfate for electrochemical studies and in distilled water for adsorption studies. The working solutions were prepared by dilution as needed.

The porous structure characteristics were obtained on the basis of low temperature nitrogen adsorption-desorption isotherms (Micromeritics ASAP 2020 volumetric adsorption analyser, Norcross, USA). The X-ray diffraction measurements were performed using an Empyrean X-ray diffractometer from PANalytical 2014 over the $2 \theta$ range from $0.3^{\circ}$ to $5^{\circ}$ with step size of $0.01^{\circ}$. Attenuated Total Reflectance (ATR-FTIR) spectra were recorded using an IR spectrometer TENSOR 27 (Brucker, 2014, Germany) equipped with diamond crystal. The spectra were recorded in the spectral range of $400-4000 \mathrm{~cm}^{-1}$. Thermal analysis was carried out on a TG-DTA/DSC apparatus (STA 449 Jupiter F1, Netzsch, Germany). The samples were heated 
from 4 to $900{ }^{\circ} \mathrm{C}$ in $\mathrm{Al}_{2} \mathrm{O}_{3}$ crucibles under oxidative (synthetic air) atmosphere with flow rate $25 \mathrm{~mL} \mathrm{~min}^{-1}$. The heating rate was $10{ }^{\circ} \mathrm{C} \cdot \mathrm{min}^{-1}$. The analysis of structure ordering of the investigated samples was conducted by electron microscopy in high resolution transmission electron microscope S/TEM Titan3 G2 60-300 (FEI Company). The Elemental CHN analysis was performed by Perkin Elmer 2400 Elemental Analyzer (1997). Cary 3E UV-Vis spectrophotometer (Varian Inc., USA) was used for absorbance measurement. Cyclic voltammetry (CV) and DPV were performed in an analytical system (Autolab, Eco Chemie, Netherlands), potentiostat/galvanostat connected to a three electrode cell, linked with a computer and with software (Eco Chemie). The system was run on a PC using GPES 4.9 software. A conventional three-electrode cell assembly consisting of a platinum wire as an auxiliary electrode and the saturated calomel electrode as a reference electrode was used. The working electrode was either an unmodified carbon paste electrode or a carbon paste electrode modified with mesoporous material (SBA-15-Sigma, SBA-15 or SBA-15- $\mathrm{NH}_{2}$ ).

\subsection{Preparation of SBA-15 materials}

Pure SBA-15 support was prepared by sol-gel technique (Zhao et al. 1998). In a typical preparation, $8.0 \mathrm{~g}$ of triblock copolymer Pluronic P123 as a structure directing agent was dissolved in $240 \mathrm{~cm}^{3}$ of $\mathrm{HCl}(2 \mathrm{~mol} / \mathrm{L})$ and $60 \mathrm{~cm}^{3}$ of $\mathrm{H}_{2} \mathrm{O}$. Mixture was stirred at $40{ }^{\circ} \mathrm{C}$ for $3 \mathrm{~h}$. Afterwards $18.32 \mathrm{~cm}^{3}$ of tetraethoxysilane (TEOS) was added dropwise. The solution was stirred for $24 \mathrm{~h}$ at the same temperature. The precipitated mixture was aged at $80{ }^{\circ} \mathrm{C}$ for $48 \mathrm{~h}$ without stirring and next the solid product was washed with distilled water and organic components were removed by calcination at $550{ }^{\circ} \mathrm{C}$ for $4 \mathrm{~h}$ in muffle furnace under an air atmosphere.

The amino-functionalized SBA-15 was prepared by post-synthesis basic treatment by aminopropyltriethoxysilane (Wang et al. 2007). For post-synthesis modification. $2.0 \mathrm{~g}$ of as-synthesized SBA-15 powder without organic template was added into a mixed solution of APTES and ethanol $\left(50 \mathrm{~cm}^{3}\right.$ ethanol $(96 \%)$ and $3 \mathrm{~cm}^{3}$ of APTES). After stirring at $25^{\circ} \mathrm{C}$ for $6 \mathrm{~h}$, the powder (denoted as SBA-15- $\mathrm{NH}_{2}$ ) was filtered, washed with distilled and gently dried at $35^{\circ} \mathrm{C}$ for $24 \mathrm{~h}$.

\subsection{Adsorption studies}

The adsorption experiments were carried out in Erlenmeyer flasks containing $0.15 \mathrm{~g}$ of silica materials and $10 \mathrm{~cm}^{3}$ of the solutions of a known concentration of 4-CP (from 50 to $\left.500 \mu \mathrm{mol} / \mathrm{dm}^{3}\right)$. The flasks were agitated for $6 \mathrm{~h}$ at a constant speed of $200 \mathrm{rpm}$ at $25^{\circ} \mathrm{C}$. At the end of this period, the mixtures were filtered through a $0.2-\mu \mathrm{m}$ pore size filter and analyzed by using UV-Vis spectrophotometry at $274 \mathrm{~nm}$. The equilibrium amount of 4-CP adsorbed per unit mass of SBA-15, $\mathrm{q}_{\mathrm{e}}(\mu \mathrm{mol} / \mathrm{g})$, was calculated by the equation:

$\mathrm{q}_{\mathrm{e}}=\frac{\left(\mathrm{C}_{0}-\mathrm{C}_{\mathrm{e}}\right) \mathrm{V}}{\mathrm{m}_{\mathrm{a}}}$

where $C_{O}$ and $C_{e}$ are the initial and the equilibrium concentration of 4-chlorophenol $\left(\mu \mathrm{mol} / \mathrm{dm}^{3}\right), V$ is the volume of the solution $\left(\mathrm{dm}^{3}\right)$ and $m_{a}$ is the mass of the adsorbent (g). All the experiments were carried out in duplicate, and average values were used for further calculations.

\subsection{Preparation of the electrodes}

A Teflon holder with a hole at one end $(2.5 \mathrm{~mm}$ diameter and $3.5 \mathrm{~mm}$ deep) for the carbon paste filling served as the electrode body. Electrical contact was made with a stainless steel rod through the center of the holder. This rod can move up and down by screw movement to press the paste down when renewal of the electrode surface is needed. Modified CPEs were prepared by thoroughly mixing 5 or $10 \mathrm{mg}$ of mesoporous material (SBA-15-Sigma, SBA-15 or SBA-15- NH2) with, respectively, 95 or $90 \mathrm{mg}$ of graphite powder (diameter $>45 \mu \mathrm{m}$ ) and, subsequently, adding $15 \mathrm{mg}$ of mineral oil $(13 \% \mathrm{~m} / \mathrm{m})$. Homogenization was then achieved by careful mixing using agate pestle and mortar and afterwards rubbed by intensive pressing with the pestle. The mixture was kept at room temperature for 2 days. The ready prepared paste was then packed into the hole of the electrode body and the carbon paste was smoothed onto a paper until it had a shiny appearance. Unmodified carbon paste electrode was prepared in a similar manner, with the addition of only $100 \mathrm{mg}$ of the same graphite powder and $15 \mathrm{mg}$ of mineral oil (Nujol).

\section{Results and discussion}

\subsection{Characterization of SBA-15 materials}

The physical properties of mesoporous silica materials were characterized using low temperature nitrogen adsorption-desorption isotherm, small-angle X-ray powder diffraction, ATR-FTIR infrared spectroscopy, thermogravimetry, SEM and TEM techniques.

Nitrogen adsorption/desorption isotherms for all silica mesoporous materials were determined at $77 \mathrm{~K}$. Figure 1 shows the nitrogen adsorption-desorption isotherms and functions of pore size distribution (PSD) (Barrett, Joyner and Halenda $(\mathrm{BJH})$ procedure 1951) obtained for the investigated samples. The shape of the sorption isotherms 

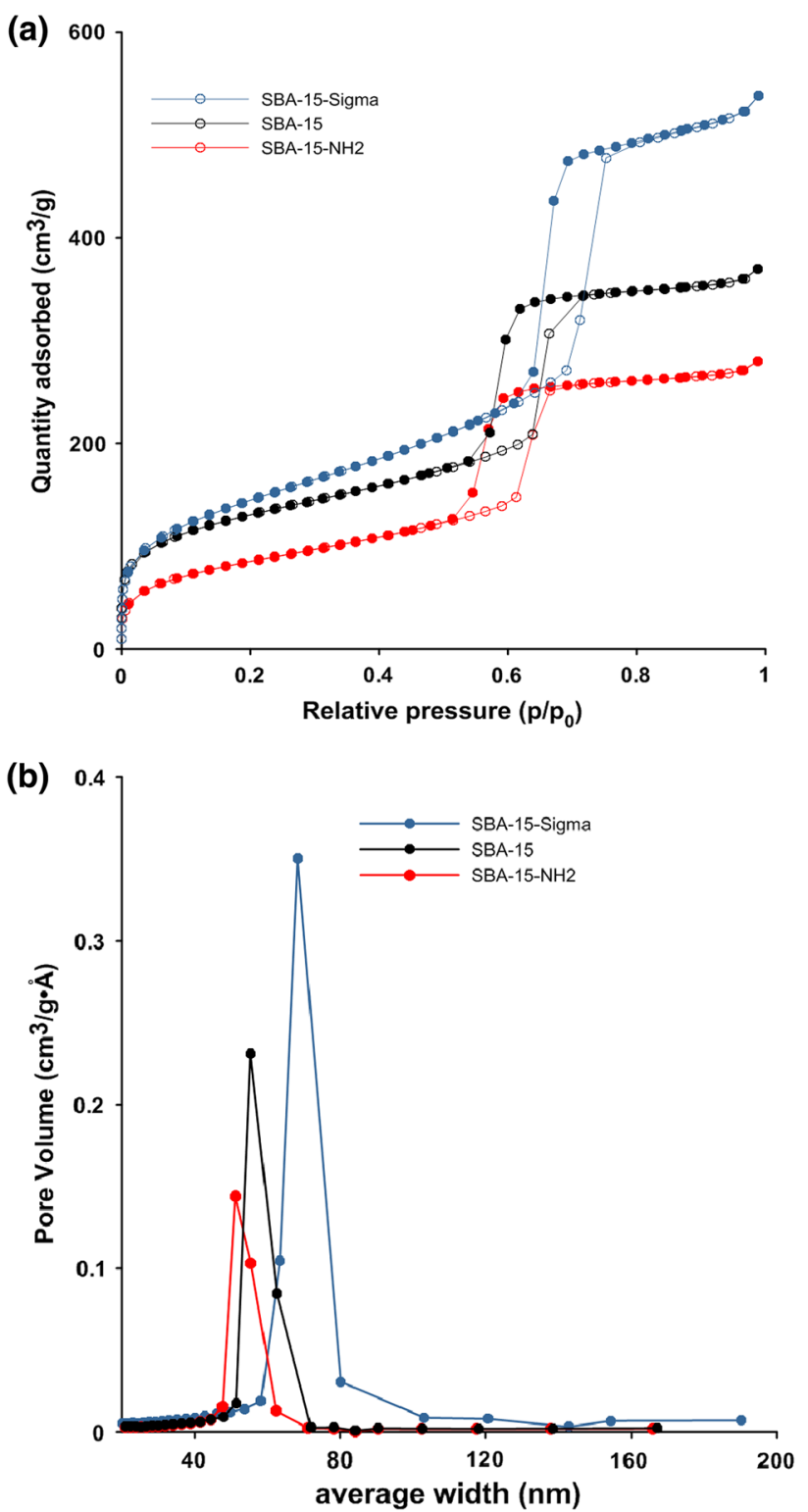

Fig. 1 a Nitrogen adsorption-desorption isotherms on SBA-15Sigma, SBA-15 and SBA-15- $\mathrm{NH}_{2}$ at $77.4 \mathrm{~K}$; b pore size distribution calculated according $\mathrm{BJH}$ method from the adsorption branch of isotherm

are typical for SBA-15 materials with ordered mesoporosity. All samples yield IV type of isotherm with $\mathrm{H} 1$ hysteresis loop in the $\mathrm{p} / \mathrm{p}_{0}$ range $0.55 \sim 0.75$. This welldefined hysteresis loop of $\mathrm{H} 1$ type rendering to the IUPAC classification (Gregg and Sing 1982) shows parallel branches of adsorption and desorption. This type of hysteresis loops is related with capillary condensation of nitrogen in similar, uniformly ordered and opened cylindrical mesopores. The presence of such structures was confirmed by $\mathrm{BJH}$ pore size calculations. As a result narrow functions characterized by a maximum at $50 \AA$ (SBA-15-NH2), $55 \AA$ (SBA-15) and $70 \AA$ (SBA-15-Sigma) what suggest presence of comparable mesopores, were obtained. After grafting of the aminopropyltriethoxysilane, the PSD decreased by $5 \AA$. The BET surface area as well as the total pore volume decreased for sample after modification. Consequently, the modification leads to a decrease of BET surface area by $210 \mathrm{~m}^{2} / \mathrm{g}$ and $157 \mathrm{~m}^{2} / \mathrm{g}$ for SBA-15-Sigma and SBA-15 respectively. Similarly, the total pore volume decreased by $0.26 \mathrm{~cm}^{3} / \mathrm{g}$ and $0.15 \mathrm{~cm}^{3} / \mathrm{g}$. A decrease of textural parameters was observed as an effect of attaching the amino groups and agrees with the other literature references (Ziarani et al. 2012). The values of specific surface areas $\left(S_{B E T}\right)$ of the materials, as well as the total pore $\left(V_{t}\right)$ and micropore $\left(V_{m i c}\right)$ volumes calculated from the adsorption isotherms are presented in Table 1. In Table the mesopore diameter $(w)$ calculated from adsorption branch of nitrogen isotherm is also given.

The ordering of porous structure of SBA-15 materials before and after modification by $\mathrm{NH}_{2}$ groups were evaluated by X-ray diffraction measurements in range of small angles $2 \theta$. The XRD patterns of SBA-15 materials are displayed in Fig. 2. In all cases the SBA-15 supports exhibit structural ordering according to hexagonal symmetry $p 6 \mathrm{~mm}$ characteristic for this type of materials. Three first and well-resolved reflections registered at small diffraction angles can be indexed as (100), (110) and (200) reflections of the hexagonal lattice and still observed after post synthesis modification. It can be observed that the three first reflections of SBA-15-Sigma sample (commercial SBA-15) are shifted slightly to lower angles. This indicates that the dimension of unit cell becomes higher than as-prepared mesoporous ordered silica. The unit cell parameters calculated from these three peaks were $10.1 \mathrm{~nm}, 10.3 \mathrm{~nm}$ and $11.0 \mathrm{~nm}$ in the case of SBA-15, SBA-15- $\mathrm{NH}_{2}$ and SBA-15-Sigma, respectively.

The FTIR spectra of all silica materials are presented in Fig. 3. The ATR-FTIR spectra of investigated samples display the typical bands of mesoporous silica materials. In all cases the absorption peaks at wavenumbers of 1042, 800 and $445 \mathrm{~cm}^{-1}$ correspond to the vibrations of $\mathrm{Si}-\mathrm{O}-\mathrm{Si}$ $\left(\mathrm{SiO}_{4}\right)$ (more specifically, $\mathrm{Si}-\mathrm{O}-\mathrm{Si}$ stretching vibrations, $\mathrm{Si}-\mathrm{O}$ bending vibrations and $\mathrm{Si}-\mathrm{O}$ out of plane deformation vibrations respectively). Moreover, on the IR spectrum of investigated samples small but characteristic bands appear at about $3745 \mathrm{~cm}^{-1}$ which are assigned to isolated silanol groups on silica surface (Morrow et al. 1976). In general after modification of mesoporous silica by amine groups, reduction of the peak intensity at $1042 \mathrm{~cm}^{-1}$ of $\mathrm{Si}-\mathrm{O}-\mathrm{Si}$ group and at $970 \mathrm{~cm}^{-1}$ of stretching $\mathrm{Si}-\mathrm{OH}$ group as well as the presence of typically hardly discernible bands of $\mathrm{NH}$ group at about $1510 \mathrm{~cm}^{-1}$ (Chong and Zhao 2003) for SBA-15- $\mathrm{NH}_{2}$ should indicate the successful modification of the silica surface. In the obtained ATR-FTIR spectra the intensity of the stretching peak of $\mathrm{Si}-\mathrm{O}-\mathrm{Si}$ as well as $\mathrm{Si}-\mathrm{O}$ 
Table 1 Porous structure parameters obtained from nitrogen adsorption isotherms $(77.4 \mathrm{~K})$

\begin{tabular}{llllll}
\hline Silica material & $S_{B E T}\left(\mathrm{~m}^{2} / \mathrm{g}\right)$ & $C$ & $w(\mathrm{~nm})$ & $V_{t}\left(\mathrm{~cm}^{3} / \mathrm{g}\right)$ & $V_{m i}\left(\mathrm{~cm}^{3} / \mathrm{g}\right)$ \\
\hline SBA-15-Sigma & 517 & 110 & 6.25 & 0.83 & 0.020 \\
SBA-15 & 464 & 183 & 5.23 & 0.57 & 0.061 \\
SBA-15-NH & 307 & 97 & 5.01 & 0.42 & 0.011 \\
\hline
\end{tabular}

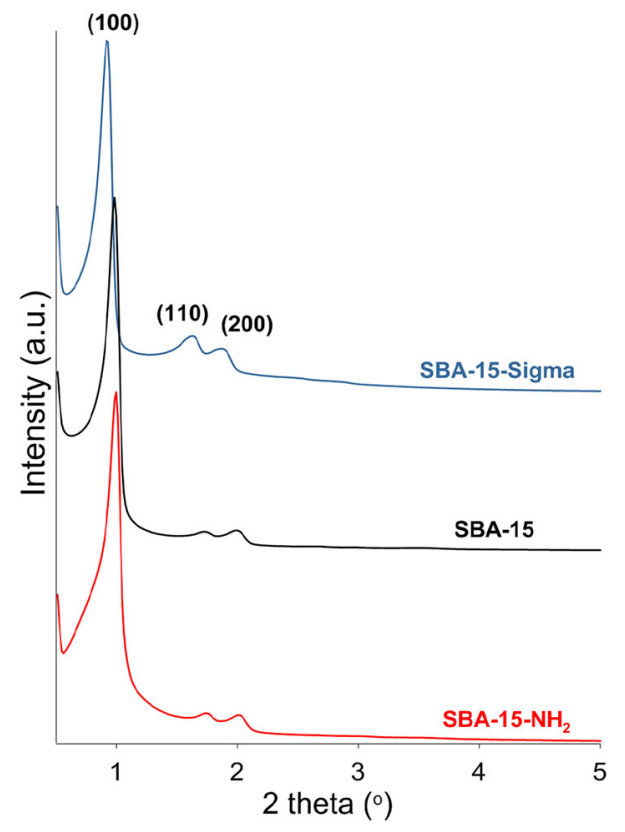

Fig. 2 The small-angle XRD patterns of mesoporous silica materials

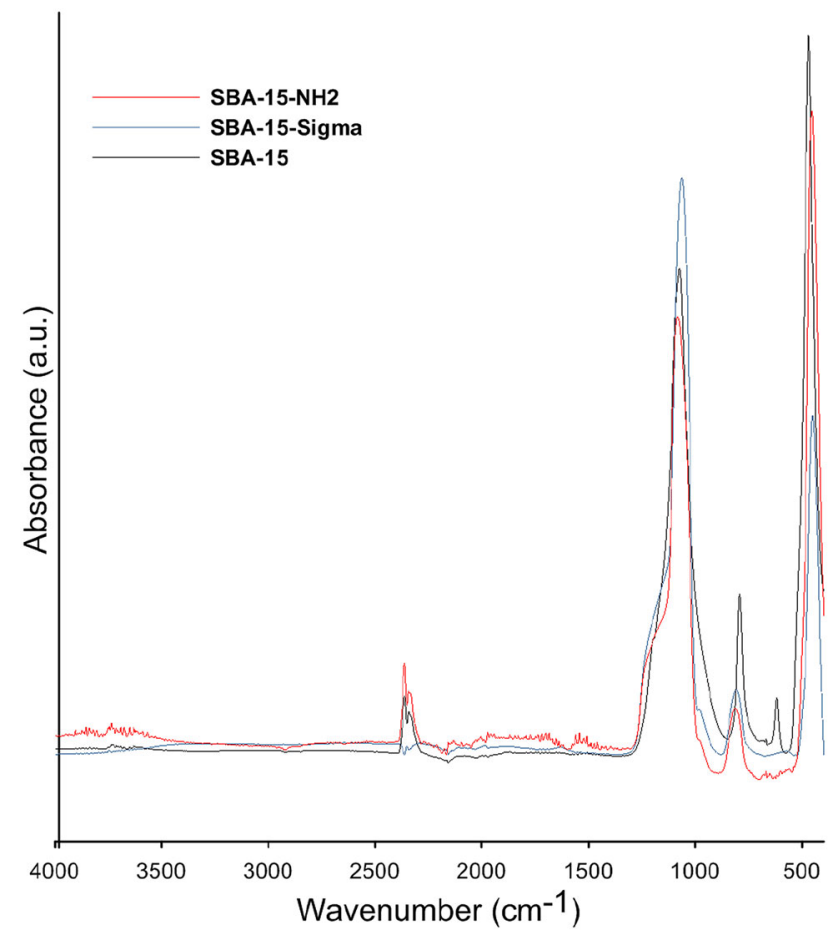

Fig. 3 ATR-FTIR infrared spectra of mesoporous ordered silica samples bending vibrations and stretching $\mathrm{Si}-\mathrm{OH}$ groups of functionalized SBA-15 decreased significantly which correlates well with the mechanism of its reaction with aminopropyltrimethoxysilane. Unfortunately, in this case an additional peak directly related to the amine groups (located at about $1542 \mathrm{~cm}^{-1}$ and describing the bending vibrations of $-\mathrm{NH}$ groups) is not clearly observed. In other words, some changes of the baseline were observed for modified sample, which may suggested presence of $-\mathrm{NH}$ bending vibrations, but the presence of a new, well-formed signal was far from obvious. It may be explained by the fact that the unequivocal characterization of this type of materials modified by amine groups using FTIR spectrometry sometimes is not so simple. Very often, these signals are very weak, even at significant content of surface localized functional groups. Regrettably, sometimes ATRFTIR technique may be not sensitive enough to observe well-defined signals from modifiers.

Elemental analysis of carbon, hydrogen and nitrogen was performed to characterize the elemental composition of SBA-15-NH2 sample. Mass percentage of CHN elements was determined for this sample as 2.83, 1.06 and $1.14 \%$, respectively.

Figure 4 shows the results of thermogravimetric analysis of unmodified and amine functionalized SBA-15 silicas as the mass loss curves and the differential thermal analysis curves. The TGA and DTA analyses of investigated samples show no significant changes in the case of unmodified mesoporous silica (SBA-15-Sigma and SBA-15). SBA-15Sigma and SBA-15 show a small weight loss whereas the SBA-15- $\mathrm{NH}_{2}$ display significantly larger weight losses due to the incorporation of amine groups.

The observed total weight loss for SBA-15-Sigma and SBA-15 are small (4.22 and $1.99 \%$ for SBA-15-Sigma and SBA-15 respectively). In this case the total weight loss can be associated with water molecules (physisorbed water and molecules eliminated by condensation of surface silanols). The observed total weight loss for SBA-15- $\mathrm{NH}_{2}$ sample was significantly higher $(6.9 \%)$ and is related to a sum of physisorbed water and grafted ammine groups. All samples were compared in Fig. 4d.

The SEM and TEM images (Fig. 5) show that the prepared SBA-15 as well as SBA-15- $\mathrm{NH}_{2}$ samples exhibit a well-ordered mesoporous channels arranged in 2D hexagonal structure according p6 mm symmetry. This structural 
Fig. 4 TGA and DTA measurements of different samples. a SBA-15-Sigma, b SBA-15, c SBA-15- $\mathrm{NH}_{2}$, d comparison of all investigated samples
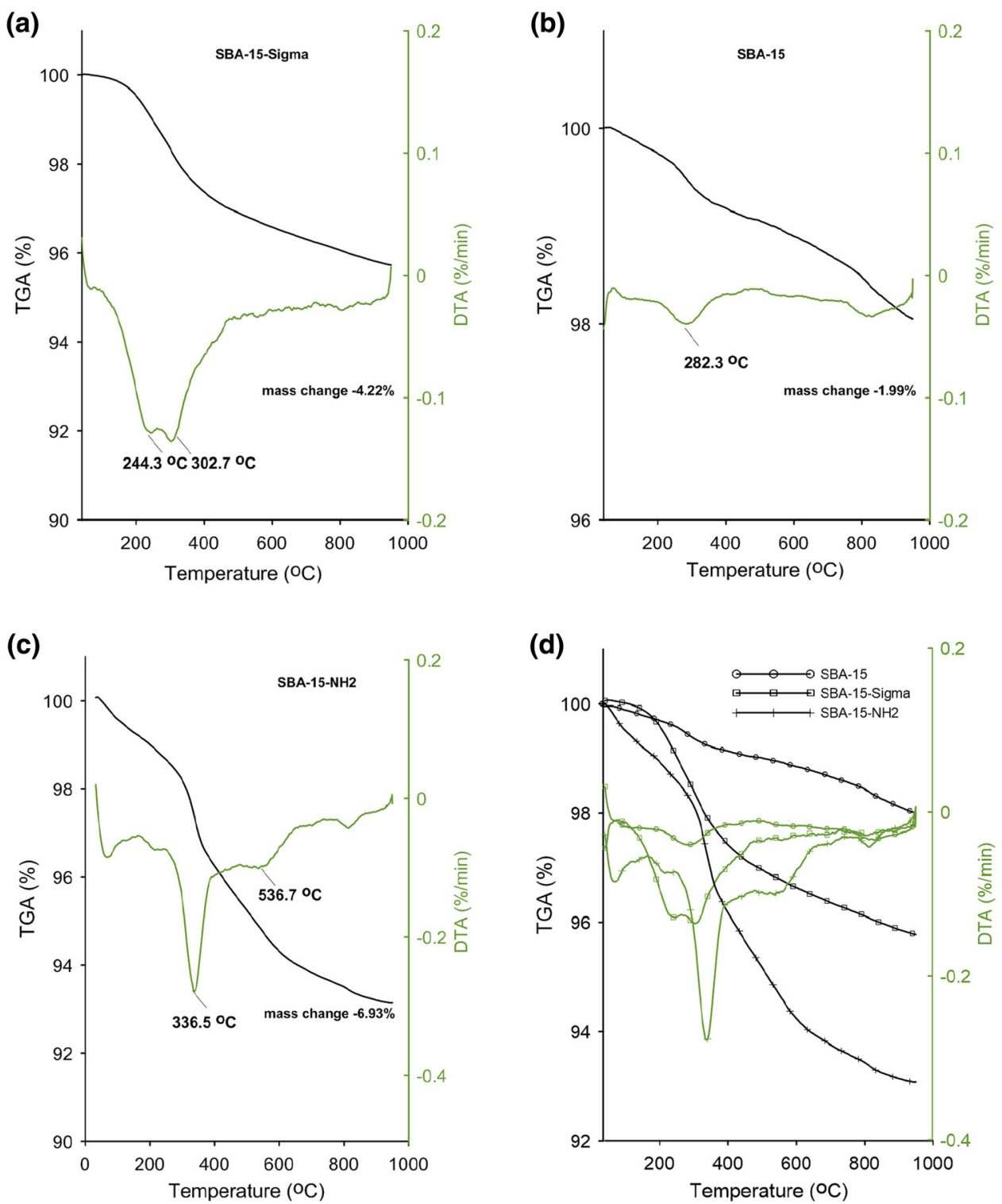

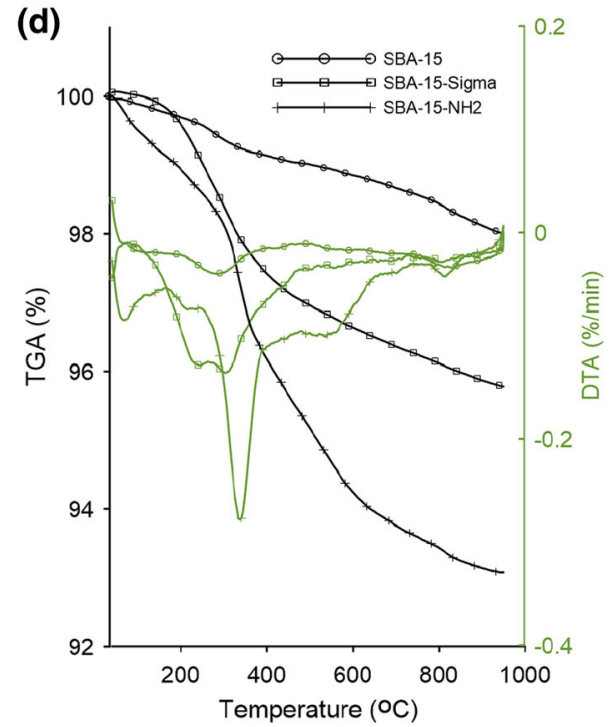

ordering of mesopores is visible in the two directions to pore axis (parallel in Fig. 5b, $\mathrm{f}$ and perpendicular in Fig. 5c, d). The distances between two cylindrical mesopores in SBA-15 sample (Fig. 5b) estimated from the TEM images are about $10.2 \mathrm{~nm}$. The diameter of mesopores and thickness of walls are about 6.2 and $4.0 \mathrm{~nm}$ respectively. In the case of SBA-15- $\mathrm{NH}_{2}$ sample the distances between two mesopores is greater $(10.5 \mathrm{~nm})$ and the diameter and thickness of walls are identified as 7.3 and $3.2 \mathrm{~nm}$ respectively.

\subsection{Adsorption of 4-CP on SBA-15}

The experimental adsorption isotherms of 4-CP on the SBA-15-Sigma, SBA-15 and SBA-15- $\mathrm{NH}_{2}$ are presented in
Fig. 6. For their analysis the Generalized Langmuir (GL) isotherm equation (Marczewski and Jaroniec 1983) derived in terms of the general theory of adsorption on energetically heterogeneous solids was applied:

$q_{e} / q_{m}=\left[\frac{\left(K C_{e}\right)^{m}}{1+\left(K C_{e}\right)^{m}}\right]^{m / n}$

where $q_{e}$ is the equilibrium adsorbed amount, $q_{m}$ is the adsorption capacity, the heterogeneity parameters $m$ and $n$ characterize the shape (width) and asymmetry of adsorption energy distribution function $(m, n \in(0,1\rangle)$, and the equilibrium constant, $K$, describes the position of distribution function on energy axis. The GL equation is reduced to simpler isotherms for specific vales of heterogeneity parameters, e.g., for $m=n$ it becomes the wellknown Langmuir-Freundlich isotherm corresponding to 
Fig. 5 a SEM image of the as synthesized SBA-15, b-d TEM images of as synthesized SBA15, e SEM image of SBA-15$\mathrm{NH} 2$ sample, $\mathbf{f}$ TEM mage of SBA-15-NH2 sample
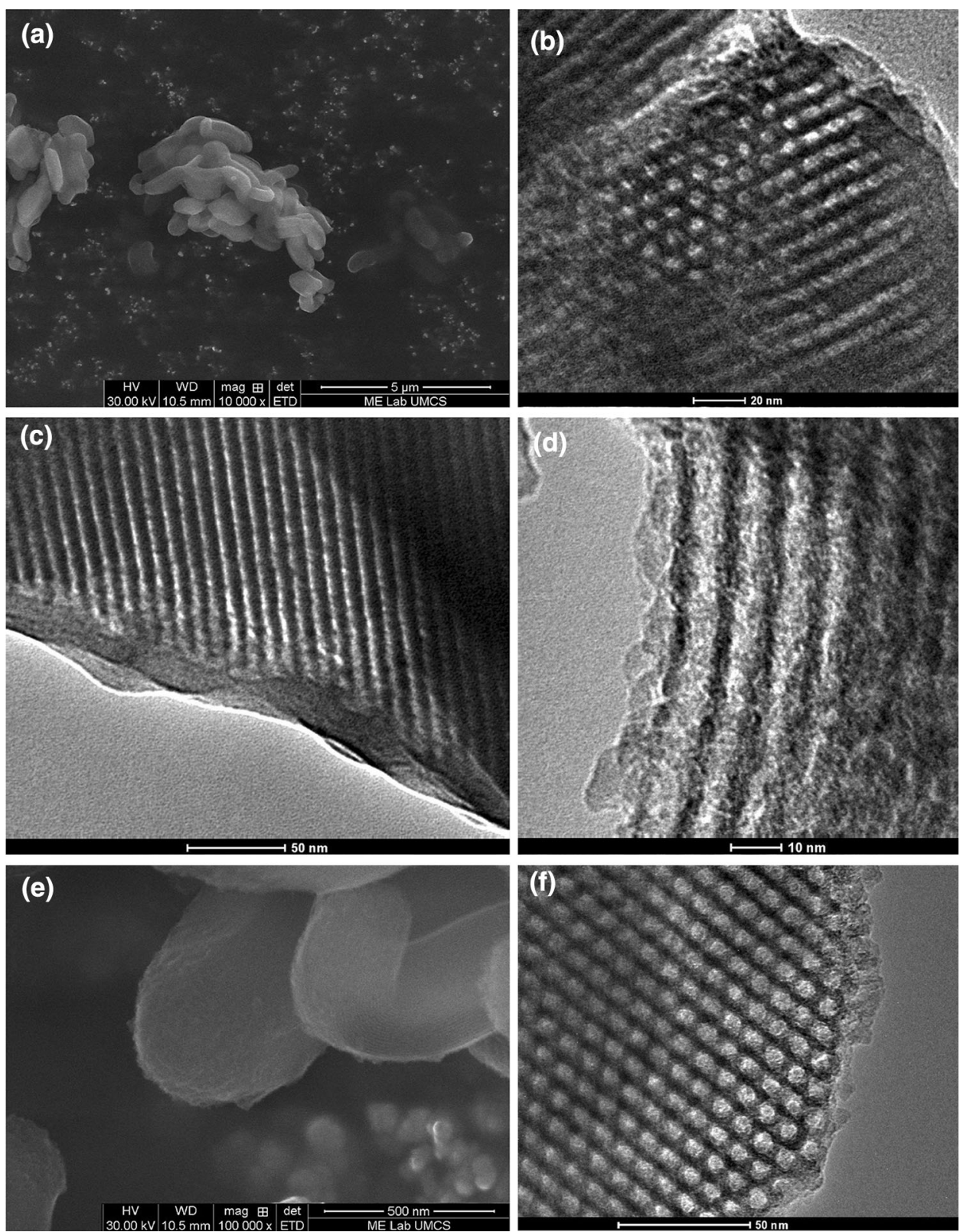

the symmetrical energy distribution, and for $m=n=1$ it is Langmuir isotherm.

The Generalized Langmuir equation was fitted to experimental data and in the case of all adsorption systems the simplest Langmuir model was found to be the best one ( $m=n=1$ ). The obtained isotherm parameters and the coefficients of determination $R^{2}$ for the adsorption of the 4-CP onto the mesoporous silica materials are presented in Table 2. The high $R^{2}$ values indicate that the equilibrium data obtained for all adsorption systems are well described by the Langmuir equation. Though typically adsorption isotherms of organics on porous solids show at least some effects of energetic heterogeneity, however, in our case due to low range of concentration, the adsorption corresponds to the high energy sites only and may be described by the Langmuir isotherm. Such a result may be also explained by a possible compensation (or even cancelling-out) of the effects of lateral interactions in adsorption space and the system nonhomogeneity (Marczewski et al. 1986, 2013). Moreover, it may be the additional effect of well-organized structure of adsorbent which diminishes the energetic and structural heterogeneity of adsorption system. The estimated adsorption capacities $\left(q_{m}\right)$ decrease in order: SBA$15-\mathrm{NH}_{2}>\mathrm{SBA}-15-$ Sigma $>$ SBA-15. The $q_{m}$ values for 4-CP adsorption on unmodified SBA-15 and SBA-15Sigma were lower in comparison to the adsorption capacity obtained for modified SBA-15- $\mathrm{NH}_{2}$. The commercial SBA15-Sigma was found to be slightly better adsorbent than 


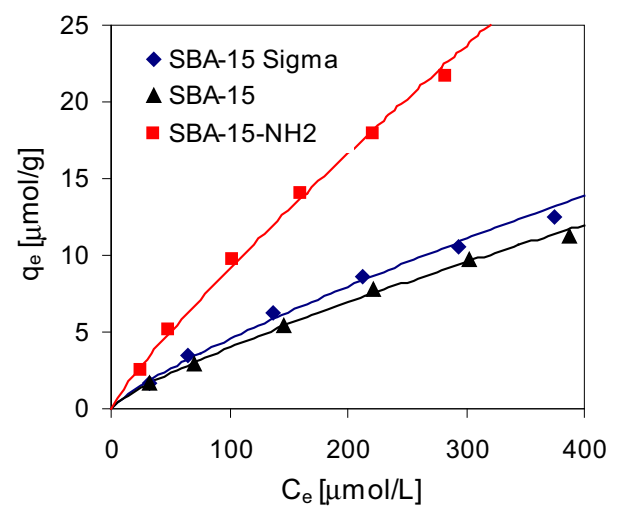

Fig. 6 Adsorption isotherms of 4-chlorophenol on mesoporous silica materials

Table 2 The Generalized Langmuir adsorption isotherm parameters and correlation coefficients $\mathrm{R}^{2}$ for adsorption of 4-chlorophenol onto mesoporous silica materials

\begin{tabular}{llll}
\hline Silica material & \multicolumn{2}{l}{ Langmuir } & \\
\cline { 2 - 4 } & $q_{e q}(\mu \mathrm{mol} / \mathrm{g})$ & $K\left(\mathrm{dm}^{3} / \mu \mathrm{mol}\right)$ & $\mathrm{R}^{2}$ \\
\hline SBA-15-Sigma & 29.3 & 0.00196 & 0.99933 \\
SBA-15 & 28.4 & 0.00161 & 0.99933 \\
SBA-15-NH 2 & 71.6 & 0.00152 & 0.999933 \\
\hline
\end{tabular}

SBA-15 which is probably due to its the greater specific surface area $\left(517\right.$ vs. $\left.464 \mathrm{~m}^{2} / \mathrm{g}\right)$. The higher adsorption capacity of SBA-15- $\mathrm{NH}_{2}$ in comparison to the unmodified silicas is a result of a more favorable interaction between 4-CP and the adsorbent due to the presence of a free electron pair and the more alkaline properties of the mesoporous silica surface. These results are consistent with the results of other authors (Anbia and Amirmahmoodi 2011; Toufaily et al. 2013; Moritz 2015) who also found that amino-functionalized SBA-15 showed higher adsorption capacities for 4-CP than the untreated SBA-15.

The adsorption of 4-CP on mesoporous SBA-15 was previously studied by Anbia and Amirmahmoodi (2011), Toufaily et al. (2013) and Moritz (2015) but the obtained results vary significantly. The adsorption isotherms of 4-CP were better described by the Freundlich equation (Anbia and Amirmahmoodi 2011) and sometimes by the Langmuir equation (Toufaily et al. 2013; Moritz 2015). The Langmuir maximum adsorption capacity values obtained for 4-CP adsorption on unmodified SBA-15 were $57.5 \mathrm{mg} / \mathrm{g}$ (Anbia and Amirmahmoodi 2011), $0.3 \mathrm{mg} / \mathrm{g}$ (Toufaily et al. 2013) and $9.6 \mathrm{mg} / \mathrm{g}$ (Moritz 2015), respectively. These differences are very large, although the specific surface areas of the materials tested are comparable $\left(812 \mathrm{~m}^{2} / \mathrm{g}\right.$ (Anbia and Amirmahmoodi 2011), $678 \mathrm{~m}^{2} / \mathrm{g}$
(Toufaily et al. 2013), $828 \mathrm{~m}^{2} / \mathrm{g}$ (Moritz 2015)). Recently, Qin et al. (2012) described adsorption of 2-chlorophenol, 2,6-dichlorophenol and 2,4,6-trichlorophenol on mesoporous SBA-15 $\left(\mathrm{S}_{\mathrm{BET}}=744 \mathrm{~m}^{2} / \mathrm{g}\right)$. The $q_{m}$ value for 2-CP adsorption was found to be $2.6 \mathrm{mg} / \mathrm{g}$. The adsorption of 4-chlorophenol was not tested but, based on the other studies of the adsorption of monochlorophenols on the carbonaceous materials (Jung et al. 2001; Hamdaoui and Naffrechoux 2007; Liu et al. 2010; Kusmierek et al. 2014) the adsorption properties of $4-\mathrm{CP}$ and $2-\mathrm{CP}$ are very similar.

All this observations show that the mesoporous SBA-15 materials reveal varying adsorption capacity towards 4-chlorophenol. In addition, despite the high specific surface areas their adsorption capacity, compared to the activated carbon, is often lower for this and other chlorophenols. For comparison, the adsorption capacity of activated carbon $\left(\mathrm{S}_{\mathrm{BET}}=925 \mathrm{~m}^{2} / \mathrm{g}\right.$ ) for 4-CP was $255 \mathrm{mg} / \mathrm{g}$ (Kusmierek et al. 2015). Of course, for other adsorbates situation may be different (heavy metals for example).

\subsection{Electrochemical studies}

\subsubsection{Effect of instrumental parameters}

In order to obtain the optimum experimental conditions, some variables affecting the peak current and peak potential were studied for the 4-CP solution of $500 \mu \mathrm{mol} / \mathrm{dm}^{3}$ on the carbon paste electrode (CPE) by the proposed voltammetric technique. The effects of the scan rate from 10 to $90 \mathrm{mV} / \mathrm{s}$ on the peak potential and the 4-chlorophenol

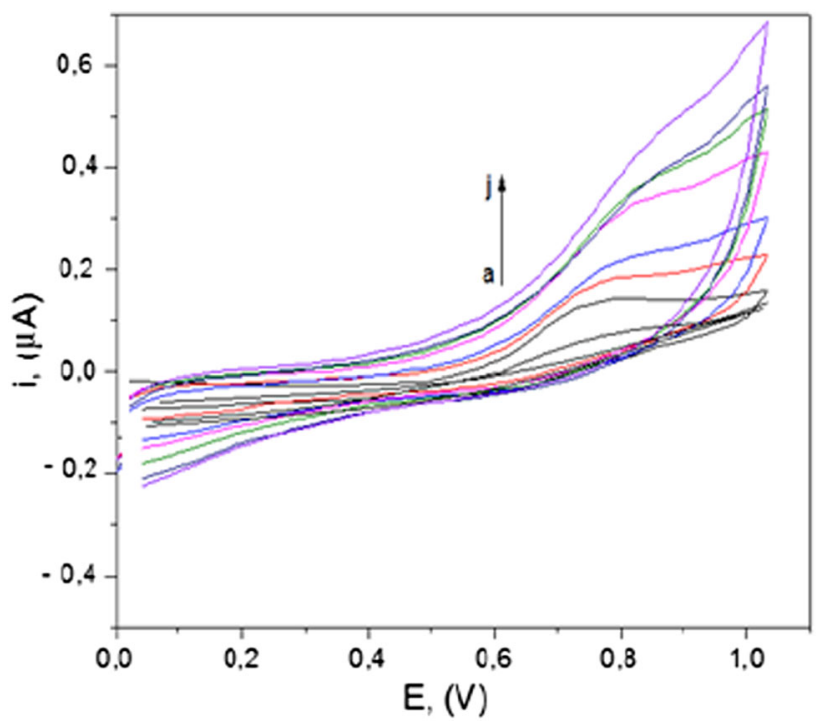

Fig. 7 The cyclic voltammograms of $500 \mu \mathrm{mol} / \mathrm{dm}^{3} 4-\mathrm{CP}$ in $0.1 \mathrm{~mol} / \mathrm{dm}^{3} \mathrm{Na}_{2} \mathrm{SO}_{4}$ on a CPE. Scan rate: a blank, b 10 , c 20 , d 30 , e 40, f 50, g 60, h 70, i 80, j $90(\mathrm{mV} / \mathrm{s})$ 
peak current were evaluated (Fig. 7). With increasing scan rate, the anodic peak current increased. The electrochemical oxidation process was carried out using cyclic voltammetry techniques $(\mathrm{CV})$. The $\mathrm{CV}$ voltammogram of 4-CP exhibited only one anodic peak, with no peak on the reverse scan, indicating the totally irreversible nature of the electrode reaction. In addition, for an irreversible oxidation process, the peak potential $E_{p}$ shifts to less positive values with the increase in scan rate.

The correlation coefficient of anodic peak current and square root of the scan rate 0.9947 (expected about 1.0) $\left(\mathrm{I}_{\mathrm{p}}=0.5311 v^{1 / 2}-0.0973\right)$, and 0.5094 which is almost close to the theoretical value of $0.5\left(\log \mathrm{I}_{\mathrm{p}}=0.5094\right.$ $\log v+0.1602$ ) slope of plot of logarithm of peak current versus logarithm of scan rate indicated that the oxidation process is predominantly diffusion-controlled (showed in Fig. 8a, b).
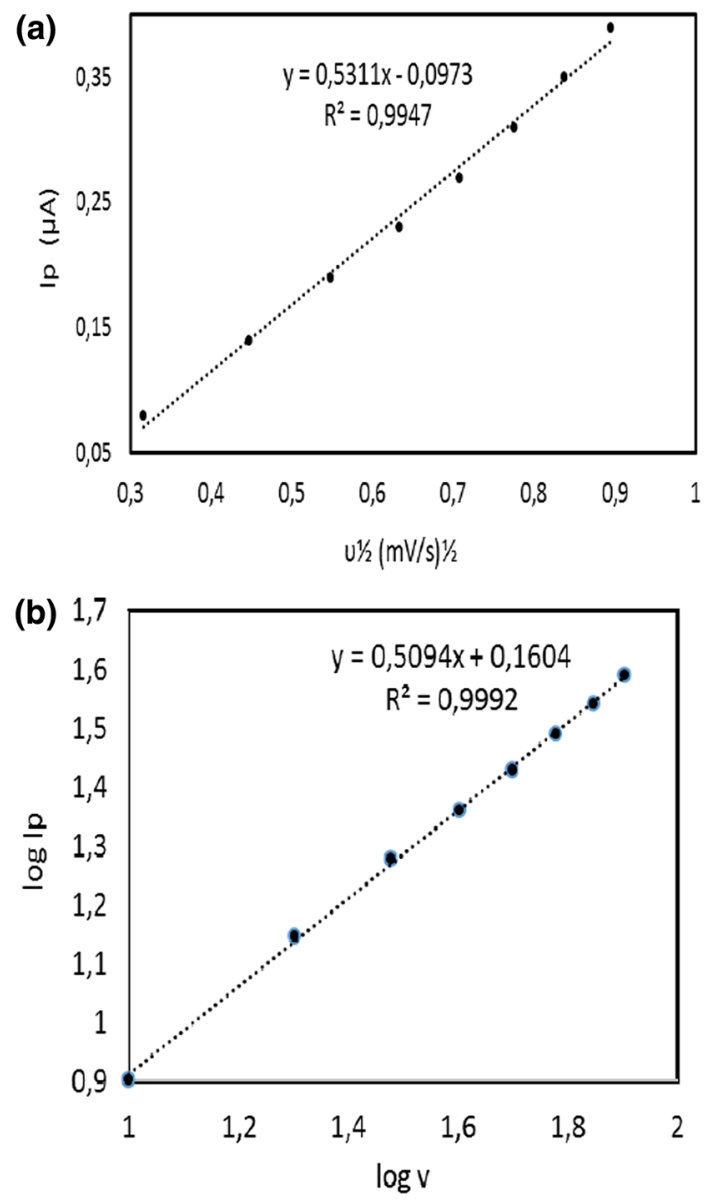

Fig. 8 The plots of square root of scan rate versus peak current (a) and logarithm of peak current versus logarithm of scan rate (b)

\subsubsection{Effect of accumulation time}

Before the DPV measurements, the influence of the accumulation time on the peak current was determined. Accumulation time was varied from $1 \mathrm{~min}$ to $8 \mathrm{~min}$ and the corresponding current value was measured using all concentrations of 4-CP solution $\left(50-500 \mu \mathrm{mol} / \mathrm{dm}^{3}\right)$. The experiments were conducted at the CPEs containing $10 \%$ of mesoporous materials. The effect of accumulation time on the peak current of $4-\mathrm{CP}\left(500 \mu \mathrm{mol} / \mathrm{dm}^{3}\right)$ is shown in Fig. 9. The peak current increased with increasing of accumulation time up to about 3-4 min and then became stable.

\subsubsection{Effect of modifier content}

Differential pulse voltammograms for the modified CPE and as an example with $500 \mu \mathrm{mol} / \mathrm{dm}^{3}$ solutions are shown in Fig. 10. From all the DPV curves (without as well as with 5 and $10 \%$ modifiers content) the peak currents and the peak potentials were determined. All the obtained values are presented in Table 3. The peak potentials reveal similar values $0.79 \pm 0.01 \mathrm{~V}$ for all the 4 -CP concentrations and both modifier's contents or the unmodified CPE. The recorded DPV curves show the dependence of the peak current on the 4-CP solution concentration. The $\mathrm{I}_{\mathrm{p}}$ exhibit increasing values with an increasing 4-CP concentration for the given CPEs modifier. The peak currents in the case of each CPEs were about two times higher when the 4-CP concentration was increased two times. The results collected in Table 3 show also the other dependence. The increase of the CPE modifier content gives an increase in the peak current. When the modifier content was enhanced (from 5 to $10 \%$ ) one could observe a peak current increase of about 1.5 times.

The results showed also that the properties of the modifier have a significant impact on the peak currents.

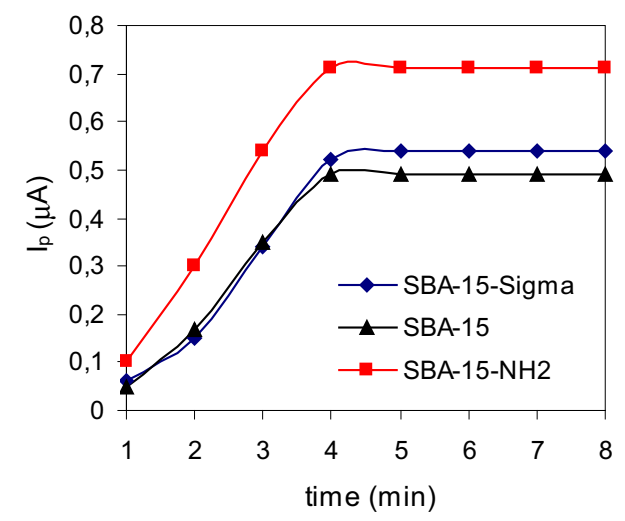

Fig. 9 Effect of accumulation time on the peak current of the 4-CP in $0.1 \mathrm{~mol} / \mathrm{dm}^{3} \mathrm{Na}_{2} \mathrm{SO}_{4}$ solution 
Fig. 10 DPV registered for $500 \mu \mathrm{mol} / \mathrm{dm}^{3} 4-\mathrm{CP}$ solutions using carbon paste electrodes containing 5 (a) and $10 \%$ (b) by mass of tested materials. Modifiers: $1-\mathrm{SBA}-15-\mathrm{NH}_{2}$, 2-SBA-15-Sigma, 3-SBA15, 4-unmodified carbon paste electrode
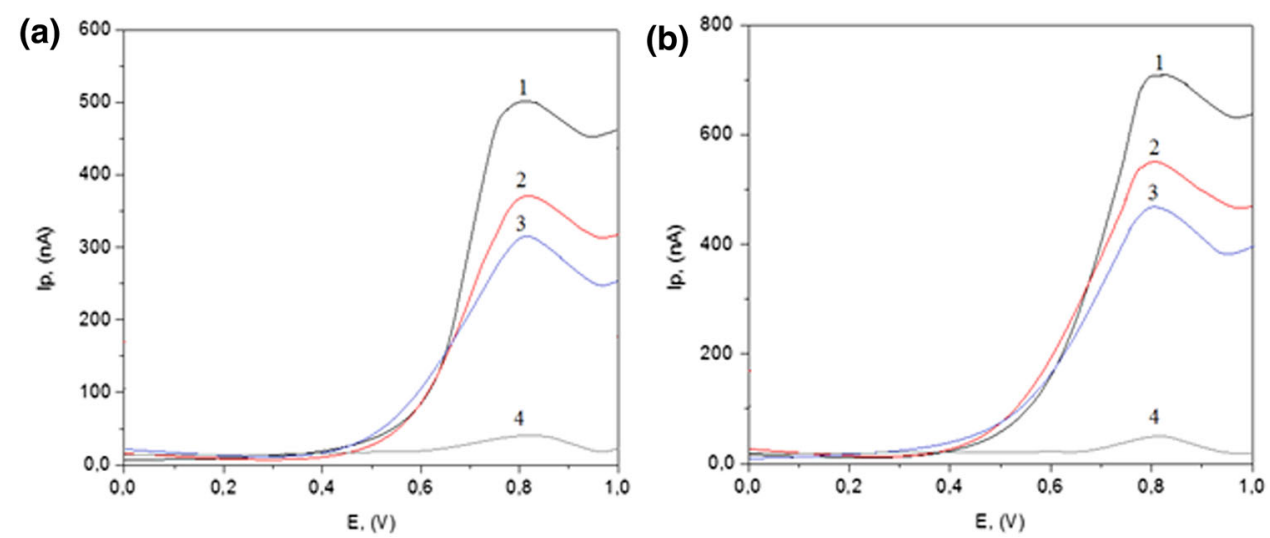

\begin{tabular}{lrlllll}
\hline Carbon paste electrode & Modifier cont. (\%) & \multicolumn{4}{l}{ Concentrations of $4-\mathrm{CP}\left(\mu \mathrm{mol} / \mathrm{dm}^{3}\right)$} \\
\cline { 3 - 6 } & & \multicolumn{2}{l}{ Peak current $(\mathrm{nA})$} & \multirow{2}{*}{ Peak potential (V) } \\
\cline { 3 - 6 } & & 500 & 250 & 100 & 50 & \\
\hline SBA-15-Sigma/CPE & 5 & 380 & 200 & 75 & 55 & 0.80 \\
SBA-15/CPE & 10 & 540 & 290 & 135 & 80 & 0.80 \\
SBA-15-NH & 5 & 340 & 170 & 72 & 40 & 0.80 \\
& 10 & 490 & 240 & 110 & 75 & 0.79 \\
& 5 & 520 & 250 & 110 & 70 & 0.79 \\
\hline
\end{tabular}

Table 3 Peak currents and potentials determined from DPV curves for carbon paste electrodes modified by adding various quantity of mesoporous materials
Under the same measurement conditions, the SBA-15Sigma was a better modifier than the SBA-15, which may be associated with its higher specific surface area and higher adsorption capacity. The positive correlation between the peak current and the specific surface area/ adsorption capacity of the modifier has also been observed for carbonaceous materials (Kusmierek et al. 2015). Significantly the best modifier of the CPEs was amino-functionalized mesoporous silica (SBA-15- $\left.\mathrm{NH}_{2}\right)$. As in the case of adsorption (Table 2) it was due to the better adsorption capacity of the SBA-15- $\mathrm{NH}_{2}$. The increase in peak current resulting from the amino-functionalization of the SBA-15 was observed also for aminophenols (Duan et al. 2013), dihydroxybenzene (Zhang et al. 2011) and naphthol isomers (Zheng et al. 2015). The higher ability to accumulate 4-chlorophenol and other phenolic derivatives results from the formation of hydrogen interaction between them and the SBA-15- $\mathrm{NH}_{2}$. In the case of 4-CP (a weak acid) it can be treat as a proton donor for $-\mathrm{NH}_{2}$ group.

\subsubsection{Validation of the method}

The limit of detection was calculated using the equation: $\mathrm{LOD}=3 \sigma / \mathrm{a}$ where " $\sigma$ " is a standard deviation of the blank signal and "a" is a slope of the calibration curve. The LOD observed for CPE modified with SBA-15/CPE was
$1.4 \mu \mathrm{mol} \mathrm{L}{ }^{-1}$ and SBA-15-NH2 $0.4 \mu \mathrm{mol} \mathrm{L}{ }^{-1}$. The limit of detection at a CTAB-MMT-modified carbon paste electrode was $0.02 \mu \mathrm{mol} \mathrm{L}{ }^{-1}$ for $2 \mathrm{~min}$ accumulation (Yang et al. 2008). However, the detection and determination of 4-CP using ordered mesoporous silica SBA-15 modified CPEs has not yet been reported.

\section{Conclusions}

This paper describes the adsorptive properties of three ordered mesoporous silicas SBA-15 and their usefulness as modifiers of the CPEs for detection of 4-chlorophenol. The adsorption isotherms of the 4-CP on the mesoporous silicas were analyzed using the Generalized Langmuir model, and its simplest form-Langmuir equation was found as the best model for analysis of the studied experimental systems. The adsorption capacities $\left(q_{m}\right)$ estimated from the Langmuir equation decreased in the order: SBA-15- $\mathrm{NH}_{2}>\mathrm{SBA}-15-$ Sigma $>$ SBA-15. All three materials were applied as the modifiers of carbon paste electrodes. The influences of the instrumental parameters, the accumulation time and the amount of the modifier were examined. The results showed that the peak current increased with the increasing of the accumulation time up to about 3-4 min and along with the amount of added modifier. Compared with the bare 
(graphite) CPE, all the mesoporous silica modified CPEs greatly increased the oxidation peak current of 4-CP, showing strong signal enhancement effects. The results demonstrated that the SBA-15- $\mathrm{NH}_{2}$ modified CPE exhibited better electroanalytic performance and higher sensitivity toward 4-CP than those at the SBA-15/CPE and SBA-15Sigma/CPE. The existence of amino groups in the channels facilitated the electron transfer between the mesoporous silica material and the electrode surface (Zhang et al. 2011). In our study for the first time such adsorption and electrochemical measurements are carried out in parallel. We have shown that the increase in sorption capacity of SBA-15 samples is accompanied by growth in the peak current recorded by DPV for the CPEs containing different amounts of added SBA-15 as a modifier. The increase of BET surface of silica and the presence of $\mathrm{NH}_{2}$ groups is accompanied by the proportional increase of both adsorption and peak current.

Open Access This article is distributed under the terms of the Creative Commons Attribution 4.0 International License (http://crea tivecommons.org/licenses/by/4.0/), which permits unrestricted use, distribution, and reproduction in any medium, provided you give appropriate credit to the original author(s) and the source, provide a link to the Creative Commons license, and indicate if changes were made.

\section{References}

Anbia, M., Amirmahmoodi, S.: Adsorption of phenolic compounds from aqueous solutions using functionalized SBA-15 as a nanosorbent. Sci. Iran. C 18(3), 446-452 (2011)

Barrett, E.P., Joyner, L.G.: Halenda P.P: The Determination of Pore Volume and Area Distributions in Porous Substances. I. Computations from Nitrogen Isotherms. J. Am. Chem. Soc. 73, 373-380 (1951)

Cesarino, I., Marino, G., do Rosário Matos, J., Cavalheiro, E.T.G.: Using the organofunctionalised SBA-15 nanostructured silica as a carbon paste electrode modifier: determination of cadmium ions by differential anodic pulse stripping voltammetry. J. Braz. Chem. Soc. 18(4), 810-817 (2007a)

Cesarino, I., Marino, G., do Rosario Matos, J., Cavalheiro, E.T.G.: Evaluation of a carbon paste electrode modified with organofunctionalised SBA-15 nanostructured silica in the simultaneous determination of divalent lead, copper and mercury ions. Talanta 75, 15-21 (2008)

Cesarino, I., Marino, G., Matos, J.R., Cavalheiro, E.T.G.: Evaluation of a carbon paste electrode modified with organofunctionalised SBA-15 silica in the determination of copper. Ecl. Quím. 32(2), 29-34 (2007b)

Clayton, G.D.: Patty's Industrial Hygiene and Toxicology. Willey, New York (1967)

Chong, A.S.M., Zhao, X.: Functionalization of SBA-15 with APTES and characterization of functionalized materials. J. Phys. Chem. B 107, 12650-12657 (2003)

Dong, S., Zhang, P., Yang, Z., Huang, T.: Simultaneous determination of catechol and hydroquinone by carbon paste electrode modified with hydrophobic ionic liquid-functionalized SBA-15. J. Solid State Electrochem. 16, 3861-3868 (2012)
Duan, S., Zhang, X., Xu, S., Zhou, C.: Simultaneous determination of aminophenol isomers based on functionalized SBA-15 mesoporous silica modified carbon paste electrode. Electrochim. Acta 88, 885-891 (2013)

Freundlich, H.M.F.: Über die Adsorption in Lösungen. Z. Phys. Chem. 57, 385-470 (1906)

Ghaffari, A., Tehrani, M.S., Husain, S.W., Anbia, M., Azar, P.A.: Adsorption of chlorophenols from aqueous solution over aminomodified ordered nanoporous silica materials. J. Nanostruct. Chem. 4, 114 (2014)

Gibson, L.T.: Mesosilica materials and organic pollutant adsorption: part A removal from air. Chem. Soc. Rev. 43, 5163-5172 (2014a)

Gibson, L.T.: Mesosilica materials and organic pollutant adsorption: part B removal from aqueous solution. Chem. Soc. Rev. 43, 5173-5182 (2014b)

Gigiena i Sanitariya. For English translation, see HYSAAV 29(10), 37, (1964)

Gregg, S.J., Sing, K.S.W.: Adsorption, Surface Area and Porosity. Academic Press, London (1982)

Guo, H., He, N., Ge, S., Yang, D., Zhang, J.: Molecular sieves materials modified carbon paste electrodes for the determination of cardiac troponin I by anodic stripping voltammetry. Microporus Mesoporus Mater. 85, 89-95 (2005)

Hamdaoui, O., Naffrechoux, E.: Modeling of adsorption isotherms of phenol and chlorophenols onto granular activated carbon Part I. Two-parameter models and equations allowing determination of thermodynamic parameters. J. Hazard. Mater. 147, 381-394 (2007)

Huirache-Acuña, R., Nava, R., Peza-Ledesma, C.L., Lara-Romero, J., Alonso-Núñez, G., Pawelec, B., Rivera-Muñoz, E.M.: SBA-15 mesoporous silica as catalytic support for hydrodesulfurization catalysts-review. Materials 6, 4139-4167 (2013)

Igbinosa, E.O., Odjadjare, E.E., Chigor, V.N., Igbinosa, I.H., Emoghene, A.O., Ekhaise, F.O., Igiehon, N.O., Idemudia, O.G.: Toxicological profile of chlorophenols and their derivatives in the environment: the public health perspective. Sci. World J. 2013, 1-11 (2013) Article ID 460215

Jung, M.W., Ahn, K.H., Lee, Y., Kim, K.P., Rhee, J.S., Park, J.T., Paeng, K.J.: Adsorption characteristics of phenol and chlorophenols on granular activated carbons (GAC). Microchem. J. 70, 123-131 (2001)

Kuśmierek, K., Sankowska, M., Skrzypczyńska, K., Świątkowski, A.: The adsorptive properties of powdered carbon materials with a strongly differentiated porosity and their applications in electroanalysis and SPME-GC. J. Colloid Interf. Sci. 446, 91-97 (2015)

Kuśmierek, K., Sankowska, M., Świątkowski, A.: Kinetic and equilibrium studies of simultaneous adsorption of monochlorophenols and chlorophenoxy herbicides on activated carbon. Desalin. Water Treat. 52, 178-183 (2014)

Langmuir, I.: The constitution and fundamental properties of solids and liquids. J. Am. Chem. Soc. 38, 2221-2295 (1916)

Lipińska, L., Jagiełło, J., Skrzypczyńska, K., Kuśmierek, K., Świątkowski, A.: Carbon paste electrodes modified with reduced graphene oxide and carbon nanotubes and their use for determination of 4-chlorophenol. Przem. Chem. 93(5), 677-680 (2014)

Liu, Q.S., Zheng, T., Wang, P., Jiang, J.P., Li, N.: Adsorption isotherm, kinetic and mechanism studies of some substituted phenols on activated carbon fibers. Chem. Eng. J. 157, 348-356 (2010)

Marczewski, A.W., Jaroniec, M.: A New Isotherm Equation for Single-Solute Adsorption from Dilute Solutions on Energetically Heterogeneous Solids. Monatsh. Chem. 114, 711-715 (1983)

Marczewski, A.W., Jaroniec, M., Deryło-Marczewska, A.: A New Method for Characterizing the Global Adsorbent Heterogeneity 
by Using the Adsorption Data. Mat. Chem. Phys. 14, 141-166 (1986)

Marczewski, A.W., Derylo-Marczewska, A., Slota, A.: Adsorption and desorption kinetics of benzene derivatives on mesoporous carbons. Adsorption 19(2-4), 391-406 (2013)

Melde, B.J., Johnson, B.J., Charles, P.T.: Mesoporous silicate materials in sensing. Sensors 8, 5202-5228 (2008)

Michałowicz, J.: The occurrence of chlorophenols, chlorocatechols and chlorinated methoxyphenols in drinking water of the largest cities in Poland. Pol. J. Environ. Stud. 14, 327-333 (2005)

Moritz, M.: Use of modified mesoporous SBA-15 silica for adsorption of 4-chlorophenol. Przem. Chem. 94(6), 872-875 (2015)

Morrow, B.A., Cody, I.A., Lee, L.S.M.: Infrared studies of reaction on oxide surfaces. 7. Mechanism of the adsorption of water and ammonia on dehydroxylated silica. J. Phys. Chem. 80, 2761-2767 (1976)

Pollino, C.A., Holdway, D.A.: Potential of two hydra species as standard toxicity test animals. Ecotoxicol. Environ. Saf. 43(3), 309-316 (1999)

Qin, Q., Liu, K., Fu, D., Gao, H.: Effect of chlorine content of chlorophenols on their adsorption by mesoporous SBA-15. J. Environ. Sci. 24(8), 1411-1417 (2012)

Raoof, J.B., Chekin, F., Ehsani, V.: Palladium-doped mesoporous silica SBA-15 modifiedin carbon-paste electrode as a sensitive voltammetric sensorfor detection of oxalic acid. Sensor. Actuat. B 207, 291-296 (2015)

Švancara, I., Walcarius, A., Kalcher, K., Vytřas, K.: Carbon paste electrodes in the new millennium. Cent. Eur. J. Chem. 7(4), 598-656 (2009)

Toufaily, J., Koubaissy, B., Kafrouny, L., Hamad, H., Magnoux, P., Ghannam, L., Karout, A., Hazimeh, H., Nemra, G., Hamieh, M., Ajouz, N., Hamieh, T.: Functionalization of SBA-15 materials for the adsorption of phenols from aqueous solution. Cent. Eur. J. Eng. 3(1), 126-134 (2013)

Vallet-Regi, M., Balas, F., Arcos, D.: Mesoporous materials for drug delivery. Angew. Chem. Int. Ed. 46, 7548-7558 (2007)

Wan, C., Zhang, Y., Lin, H., Wu, K., Chen, J., Zhou, Y.: Electrochemical determination of p-chlorophenol based on the surface enhancement effects of mesoporous $\mathrm{TiO}_{2}$-modified electrode. J. Electrochem. Soc. 156(11), F151-F154 (2009)

Wang, L., Ma, L., Wang, A., Liu, Q., Zhang, T.: $\mathrm{CO}_{2}$ adsorption on SBA-15 modified by aminosilane. Chinese J. Catal. 28, 805-810 (2007)
Wang, S.: Ordered mesoporous materials for drug delivery. Microporus Mesoporus Mater. 117, 1-9 (2009)

Xie, X., Sun, D., Liu, G., Zeng, Q.: Sensitive and rapid determination of diethylstilbestrol using mesoporous SBA-15 modified electrode. Anal. Methods 6, 1640-1644 (2014)

Xie, Y.W., Sharma, K.K., Anan, A., Wang, G., Biradar, A.V., Asefa, T.: Efficient solid-base catalysts for aldol reaction by optimizing the density and type of organoamine groups on nanoporous silica. J. Catal. 265, 131-140 (2009)

Yang, H., Zheng, X., Huang, W., Wu, K.: Modification of montmorillonite with cationic surfactant and application in electrochemical determination of 4-chlorophenol. Colloids Surf. B 65 , 281-284 (2008)

Yi, H., Li, Z., Li, K.: Application of mesoporous $\mathrm{SiO}_{2}$ modified carbon paste electrode for voltammetric determination of epinephrine. Russ. J. Electrochem. 49(11), 1073-1080 (2013)

Zhang, P., Dong, S., Gu, G., Huang, T.: Simultaneous determination of $\mathrm{Cd}^{2+}, \mathrm{Pb}^{2+}, \mathrm{Cu}^{2+}$ and $\mathrm{Hg}^{2+}$ at a carbon paste electrode modified with ionic liquid-functionalized ordered mesoporous silica. Bull. Korean Chem. Soc. 31(10), 2949-2954 (2010)

Zhang, X., Duan, S., Xu, X., Xu, S., Zhou, C.: Electrochemical behavior and simultaneous determination of dihydroxybenzene isomers at a functionalized SBA-15 mesoporous silica modified carbon paste electrode. Electrochim. Acta 56, 1981-1987 (2011)

Zhao, D., Feng, J., Huo, Q., Melosh, N., Fredrickson, G.H., Chmelka, B.F., Stucky, G.D.: Triblock copolymer syntheses of mesoporous silica with periodic 50 to 300 angstrom pores. Science 279, 548-552 (1998)

Zhang, L.X., Yu, C.C., Zhao, W.R., Hua, Z.L., Chen, H.R., Li, L.: Preparation of multi-amine-grafted mesoporous silicas and their application to heavy metal ions adsorption. J. Non-Cryst Solids 353, 4055-4061 (2007)

Zheng, X., Duan, S., Liu, S., Wei, M., Xia, F., Tian, D., Zhou, C.: Sensitive and simultaneous method for the determination of naphthol isomers by an aminofunctionalized, SBA-15-modified carbon paste electrode. Anal. Methods 7, 3063-3071 (2015)

Ziarani, G.M., Badiei, A., Mousavi, S., Lashgari, N., Shahbazi, A.: Application of Amino-Functionalized SBA-15 Type Mesoporous Silica in One-Pot Synthesis of Spirooxindoles. Chin. J. Catal. 33, 1832-1839 (2012) 